UNDERGRADUATE RESEARCH IN NATURAL AND CLINICAL SCIENCE AND TECHNOLOGY (URNCST) JOURNAL Read more URNCST Journal articles and submit your own today at: https://www.urncst.com

\title{
2021 Connecting Young Minds (CYM) Undergraduate Research Conference: 5-Minute Research Presentations
}

Stephanie Bogdan, BScH Student [1]*, Zain Saleem, BHSc Student [2], Michelle Gandelman, BScH Student [1]

[1] Faculty of Medicine, University of Ottawa, Ottawa, Ontario, Canada K1N 6N5

[2] Faculty of Health Sciences, University of Ottawa, Ottawa, Ontario, Canada, K1N 6N5

*Corresponding Author: sbogd011@uottawa.ca

\begin{abstract}
Connecting Young Minds (CYM) is an annual bilingual student-led research conference held at the University of Ottawa. Our mission is to encourage undergraduate students to network with professors, present their research, and gain experience drafting scientific literature. The conference engages the interests of students in the sciences through presentations held by keynote speakers, interactive breakout rooms with graduate level students, and a research-based competition. Each year, CYM hosts a 5-minute research presentation competition in which ten candidates are selected by a panel of judges based on the submission of an abstract pertaining to their research. The competition provides an opportunity for undergraduate students to highlight their research findings to an audience and series of judges in a concise and engaging manner. Abstracts in this booklet were submitted by participants on a volunteer basis.
\end{abstract}

Keywords: undergraduate research conference; science; abstract competition; undergraduate studies; bilingual conference; Connecting Young Minds

Table of Contents

Connecting Young Minds 5-Minute Research Presentation Abstracts.....

pg. A01-A05

\section{Conference Abstracts}

Note: These abstracts have been reproduced directly from the material supplied by the authors, without editorial alteration by the staff of the URNCST Journal. Insufficiencies of preparation, grammar, spelling, style, syntax, and usage are the authors.

\section{Connecting Young Minds 5-Minute Research Presentation Abstracts}

Effects of age-related macrophage dysfunctions on atherosclerosis regression Issraa Suliman, BSc Student [1], Mireille Ouimet PhD [2]

[1] Department of Cellular and Molecular Medicine, University of Ottawa, Ottawa, Ontario, Canada K1Y 4W7

[2] Department of Biochemistry, Microbiology and Immunology, University of Ottawa, Ottawa, Ontario, Canada K1Y 4W7

Atherosclerosis is defined by the buildup of plaque in the artery wall, causing the narrowing of arteries. Studies revealed the causative role of monocytes in the development of plaques as they infiltrate the subendothelial layer of the vessel, differentiate into macrophages and engulf excess lipids. These events contribute to atherosclerosis progression, a process by which early lipid-rich lesions gradually develop into rupture-prone plaques. In contrast, atherosclerosis regression is defined as the reduction of one or more standard plaque parameters, including size, lipid content and inflammation. In response to excess lipids, aged macrophages showed an impaired energy metabolism, dysfunctional autophagy and an altered capacity to transition from M1 to M2 phenotype. While these processes were shown to contribute to plaque regression, the effects of age-related macrophage dysfunctions and their impact on plaque regression remain unknown. We hypothesize that aged macrophages impair regression through age-related dysfunctions of autophagy and M1 phenotypic presentation. To test this, we compared the capacity of autophagy in non-loaded and aggregated-LDL (agLDL)-loaded aged and young macrophages collected from peritoneal and bone marrow of 3-months and 2-years old mice. RT-qPCR and western blot revealed that autophagy is more activated in aged macrophages as compared to young. However, agLDL-loaded aged macrophages exhibited impaired cell metabolism. Together, our results identify differential autophagy gene expression, autophagy flux and cell metabolism in aged 


\section{UNDERGRADUATE RESEARCH IN NATURAL AND CLINICAL SCIENCE AND TECHNOLOGY (URNCST) JOURNAL}

Read more URNCST Journal articles and submit your own today at: https://www.urncst.com

as compared to young macrophage foam cells, highlighting the need to better understand atherosclerosis regression in the aged environment, to guide the development of therapies targeted towards our aging population.

Towards ambiphilic chemistry with phosphonium ylides

Nathan E. Comin, BSc Student [1], Marc-André Légaré, PhD [2]

[1] Department of Chemistry and Biomolecular Sciences, University of Ottawa, Ottawa, Ontario, Canada K1N 6N5

[2] Department of Chemistry, McGill University, Montréal, Québec, Canada H3A OG4

While catalysis is considered one of the pillars of green chemistry, it often relies on naturally scarce elements, notably from the transition metal family. Because of the toxicity, price, and extraction issues associated with these precious elements, the development of green catalysts based on earth-abundant elements has become increasingly attractive. Towards this goal, we studied a family of phosphorus-containing complexes for the activation of organic molecules, taking steps towards the development of new metal-free catalytic processes. Computational chemistry was used to screen for promising systems which were targeted for synthesis in the laboratory. The ambiphilic nature of phosphonium ylides was found to be key in the reactivity and the addition of electron withdrawing groups in particular made them very effective. There is strong potential for reactions with multiple-bonded functional groups in two- and three-molecule systems.

Correcting the R506Q mutation of Factor V Leiden in model derived iPSCs by employing CRISPR Cas9 as a novel preventative strategy

Zeynep Cildir, BSc Student [1], Ragav Chona, BSc Student [1], Kasuni Pillagawa, BSc Student [2], Malithi Thanthrige, BSc Student [1]

[1] Faculty of Medicine, University of Ottawa, Ottawa, Ontario, Canada K1N 6N5

[2] Department of Biomedical Science, University of Ottawa, Ottawa, Ontario, Canada K1N 6N5

Factor V Leiden (FVL), is an autosomal dominant genetic disorder characterized by a defective anticoagulant response, increasing one's susceptibility to venous thromboembolism by 50\%. FVL patients exhibit increased rates of ischemic stroke and myocardial infarction because of a point mutation (R506Q) on the factor V (FV) gene G1691A in exon 10, which alters the coagulation system by inactivating the recognition and cleavage abilities of activated protein C (APC). This causes the clots to remain longer than usual, increasing the possibility of an embolism. Generally, FVL patients are subject to debilitating cerebrovascular conditions that permanently damage vascular tissue. Diagnosis typically occurs after damage and treatment options are limited to blood thinners. Employing CRISPR and iPSCs as a preventative gene therapeutic measure could reverse effects of FVL at a molecular level. Peripheral blood mononuclear cells are extracted from mice and reprogrammed into iPSCs. To remove R506Q on G1691A, SpCas9 and sgRNA expression vectors are created, coupled with homology arms containing exon 10 with the corrected FV gene, and Cas9/gRNA ribonucleoprotein (RNP) to cleave the strand. The targeting construct is knocked in using homology directed repair and its incorporation is verified by PCR/sequencing. Electroporation transfects the targeting vector and RNP complex into iPSCs. These gene edited iPSCs are differentiated into hepatocyte like cells (HLCs) and tested for FV antigen levels before and after knock in. Recovered clotting activity of FV with gene corrected HLCs is expected. Ultimately, current pharmacological interventions are temporary; however, this novel preventative strategy reverses effects of FVL, providing a permanent treatment to allow the normal functioning of FV. 
UNDERGRADUATE RESEARCH IN NATURAL AND CLINICAL SCIENCE AND TECHNOLOGY (URNCST) JOURNAL Read more URNCST Journal articles and submit your own today at: https://www.urncst.com

\author{
Adverse events and length of stay following laparoscopic paraesophageal hernia repair \\ Sami A. Abdul, BScH Student [1,3,4], David L. Nguyen BSc Student [3,4], Aziza A. Rawahi MD [3,4], \\ Caitlin Anestee, BA[3,4], Edita Delic [3,4], Sebastian Gilbert, MDCM [2-4], Sudhir, Sundaresan, MD[2-4], \\ Patrick J. Villeneuve, MDCM, PhD[2-4], Donna E. Maziak, MDCM, MSc [2-5], Andrew J.E. Seely, MDCM, PhD[2-5] \\ [1] Department of Biology, University of Ottawa, Ottawa, Ontario, Canada, K1N 6N5 \\ [2] Department of Surgery, University of Ottawa, Ottawa, Ontario, Canada, K1H 8L6 \\ [3] Division of Thoracic Surgery, The Ottawa Hospital, Ottawa, Ontario, Canada, K1H 8L6 \\ [4] Clinical Epidemiology Program, Ottawa Hospital Research Institute, Ottawa, Ontario, Canada, K1H 8 L6 \\ [5] School of Epidemiology and Public Health, University of Ottawa, Ottawa, Ontario, Canada, K1H 8 L1
}

Objective reporting of postoperative adverse events (AEs) following laparoscopic paraesophageal hernia repair (LPEHR) is limited and essential for quality assessment of surgical care, as well as the impact (if any) of antireflux technique (Dor vs. Nissen) and use of mesh cruroplasty. All patients undergoing LPEHR (January 2008 to April 2020) underwent prospective monitoring of AE incidence and severity, categorized by the Thoracic Morbidity \& Mortality Classification System (based on Clavien-Dindo schema) during postoperative recovery. Of the 99 patients included, $28(28.3 \%)$ experienced at least one AE, comprising Grades I (17\%), II (50\%), IIIa (21\%), and IIIb (11\%); there were no Grades IV or V AEs. Atrial arrhythmias $(\mathrm{n}=$ $6)$, myocardial ischemia $(n=3)$, and infections $(n=3)$ were the most frequent complications. $9.1 \%$ of patients had a prolonged LOS (PLOS), and 1\% required readmission. The choice of fundoplication or mesh cruroplasty had no effect on AE rates. 94 subjects underwent fundoplication where Dor (71.3\%) had a trend towards reduced median LOS (median [interquartile range]) 2 [2-4] as compared to Nissen $(28.7 \%) 3$ [3-4] days $(\mathrm{P}=0.15) .94$ subjects underwent crural repair with mesh $(31.9 \%)$ or no mesh $(68.1 \%)$, with a LOS of 3 [2-4] and 2 [2-4] days $(\mathrm{P}=0.5)$. This study highlights that a third of patients undergoing LPEHR will experience a postoperative AE, one tenth will have a PLOS, and $1 \%$ require re-admission, with no significant impact based on type of fundoplication or mesh cruroplasty.

Development of selective irreversible peptidomimetic Factor XIIIa inhibitors through systematic variation of linker chain length \& warhead functionality

Kian Mansour, BSc Student [1], Eric W. J. Gates, PhD [1], Jeffrey W. Keillor, PhD [1]

[1] Department of Chemistry and Biomolecular Sciences, University of Ottawa, Ottawa, Ontario, Canada, K1N 6N5

Current anticoagulants employed for the management of venous thrombosis and coronary artery disease inhibit thrombin or Factor $\mathrm{Xa}$, key enzymes in the blood clotting cascade. Though effective, these treatments preclude soft clot formation, increasing bleeding risks. There exists a need to develop anticoagulants which permit soft clot formation; Factor XIIIa (FXIIIa), a transglutaminase enzyme responsible for solidifying clots in the cascade's final step, is a promising inhibition target. Previously reported FXIIIa inhibitors function by trapping the active site's Cys thiolate with an electrophilic warhead carried by a peptidomimetic scaffold; these compounds lack selectivity over human tissue transglutaminase (hTG2), a ubiquitously expressed isozyme. The present work aims to design irreversible peptidomimetic FXIIIa inhibitors with higher selectivities over hTG2. Differences in the isozymes' binding pocket depths suggest that shortening the linker length between the warhead and peptide could increase selectivity for FXIIIa. A series of 8 inhibitors with linkers of 1-4 methylene units leading to either acrylamide or $\alpha$-chloroacetamide warheads were designed based on previous scaffolds. Compounds were produced through solution-phase organic synthesis and solid-phase peptide synthesis, and subsequently evaluated for activities against both isozymes through fluorescence-quenching and colorimetric assays. Preliminary kinetic results indicate reactivity differences as linker length is altered, displaying the importance of this structural consideration in inhibitor design. Warhead comparisons are underway, and will be reported in due course. These findings will aid in the development of the next generation of FXIIIa inhibitors, and in the design of fluorescent probes for the further study of the structure and function of FXIIIa.

Investigating the role of LAG3 expression in natural killer cells Valeria Vasilyeva, BSc Student [1,2], Marie Marotel, PhD [1,2], Michele Ardolino, PhD [1,2]

[1] Department of Biochemistry, Microbiology, and Immunology, University of Ottawa, Ottawa, Ontario, Canada K1H 8M5

[2] Cancer Therapeutics Program, Ottawa Hospital Research Institute, Ottawa, Ontario, Canada K1H 8L6

Natural killer (NK) cells are effector lymphocytes that protect the body from infections and tumors by secreting inflammatory mediators and cytotoxic molecules. Under chronic stimulation in cancer and viral infections, NK cells experience a decrease in these functions, a phenomenon called exhaustion. Exhausted NK cells often upregulate immune checkpoint receptors, including LAG3. LAG3 is known to inhibit T cell function, but its role in NK cells is unknown. We hypothesize that LAG3 is 
UNDERGRADUATE RESEARCH IN NATURAL AND CLINICAL SCIENCE AND TECHNOLOGY (URNCST) JOURNAL Read more URNCST Journal articles and submit your own today at: https://www.urncst.com

a driving force of NK cell exhaustion, and we are interested in discovering the underlying mechanisms. Using flow cytometry, we analyze the differences in functionality, signaling pathways, and metabolism between NK cells expressing or not LAG3 in murine models of infection and cancer. As expected, LAG3+ NK cells were less functional. However, when we performed the mechanistic studies, surprisingly, we observed that LAG3 + NK cells displayed increased activity of the MAPK, mTOR, and metabolic pathways. This may suggest that LAG3+ NK cells are not undergoing exhaustion, but, instead, the cells are shifting their efforts away from their host defensive functions to perform other cellular functions. Our next steps are to replicate these experiments and test the effects of deleting the LAG3 gene from NK cells. The discovery of the role of LAG3 in NK cell exhaustion can ultimately contribute to immune checkpoint blockade therapies that are currently undergoing clinical trials for the treatment of cancer.

Evaluation of fluorescent properties in an organometallic dual-lanthanide compound Neerav Mullur, BSc Student [1,2], Adam J. Shuhendler, PhD [2]

[1] Faculty of Medicine, University of Ottawa, Ottawa, Ontario, Canada K1N 6N5

[2] Department of Chemistry and Biomolecular Sciences, University of Ottawa, Ottawa, Ontario, Canada K1N 6N5

Fluorescence imaging is a widely employed tool in clinical and pre-clinical research. From imaging subcellular structures to organs and organ systems, fluorescent probes are vital for the progression of science and medicine. Lanthanide-organic complexes have favourable luminescent characteristics, namely strong emissions over narrow wavelength ranges, and excitation over a range of wavelengths. The organic ligand is thought to act as an antenna, absorbing incident light and subsequently exciting the lanthanide ions through energy transfer. The lanthanide ion then undergoes emission, producing the desired luminescent qualities. Here we focus on determining the luminescent properties of an organometallic complex comprised of an organic ligand chelating two lanthanide ions. Four water-soluble compounds were synthesized and characterized by mass spectrometry (MS), and nuclear magnetic resonance spectroscopy (NMR) methods. These compounds are composed of a conserved organic ligand, with two lanthanide ions each. The four lanthanide ion pairs are $\mathrm{Eu}(\mathrm{III})-\mathrm{Gd}(\mathrm{III})$, $\mathrm{Eu}(\mathrm{III})-\mathrm{Yb}(\mathrm{III}), \mathrm{Eu}(\mathrm{III})-\mathrm{Lu}(\mathrm{III})$, and $\mathrm{Lu}(\mathrm{III})-\mathrm{Lu}(\mathrm{III})$. Eu(III) complexed with organic ligands is typically luminescent, and most of the luminescence is hypothesized to come from that lanthanide ion. $\mathrm{Lu}(\mathrm{III})$ is optically inactive, thus the $\mathrm{Lu}$ (III)- $\mathrm{Lu}$ (III) compound will be used to determine the luminescent properties of the organic molecule without emission from a lanthanide, while maintaining the overall charge and retaining many organometallic properties of the molecule. Fluorescence excitation and emission spectra will be taken and used to evaluate the luminescent properties of the compounds. These compounds will be followed up with in vitro and in vivo studies to evaluate their use as probes for molecular imaging.

Assessing individual and collective effects of inhibiting E6/E7 HPV proteins and additionally induced DNA damage on p53-induced apoptosis in HeLa cells

Ruiyan Gao, BSc Student [1], Keith Wheaton, PhD [2], Lisa D'Ambrosio, PhD [2], Elizabeth Williams, PhD [2]

[1] Faculty of Medicine, University of Ottawa, Ottawa, Ontario, Canada K1N 6N5

[2] Department of Biochemistry, Microbiology, and Immunology, University of Ottawa, Ottawa, ON, Canada K1N 6N5

The p53 tumor suppressor is a well-studied transcription factor that becomes activated in cells with DNA damage, playing a crucial role in suppressing tumorigenesis. In healthy cells, the MDM2 ubiquitin ligase mediates p53 degradation to prevent apoptosis. However, in HPV-induced cervical cancer cells, the HPV virus will induce the expression of an ubiquitin ligase called E6 to accelerate p53 degradation and allow for continuous cancer development. Previous studies on the inhibition of the E6 protein alone claimed it insufficient in achieving proper p53 activation. Here, we compared individual and collective effects of inhibiting the E6 protein, as well as the introduction of additional DNA damage in Hela cells. We hypothesized the introduction of DNA damage or the inhibition of E6 alone will have similar effects on p53 activation, but will lead to increased levels in the combined treatment. Through indirect immunoblotting, quantitative PCR using GAPDH as a control gene, and immunofluorescence microscopy using $\gamma-\mathrm{H} 2 \mathrm{AX}$ and C-CASP3 as molecular markers for early stages of apoptosis, the assessments of p53 activation and expression reveal that the introduction of additional DNA damage alone is a more significant contributor to p53-induced apoptosis than the inhibition of the E6 ubiquitin ligase, while the combination of additional DNA damage and E6 inhibition led to a significantly increased level of p53 expression and activation in HeLa cells. The quantification of $\mathrm{p} 53$ activation in this project provides insight to a more beneficial treatment method for HPV-induced cervical cancer, and should be further experimented in clinical settings. 
UNDERGRADUATE RESEARCH IN NATURAL AND CLINICAL SCIENCE AND TECHNOLOGY (URNCST) JOURNAL Read more URNCST Journal articles and submit your own today at: https://www.urncst.com

Scriptomic evaluation of the translatability of new treatments in triple-negative breast cancer Ammar H. Salkini, BSc Student [1], Lisheng Wang, PhD [1,2,3]

[1] Department of Biochemistry, Microbiology, and Immunology, University of Ottawa, Ottawa, Ontario, Canada K1H 8M5

[2] Ottawa Institute of Systems Biology, Ottawa, Ontario, Canada K1H 8M5

[3] The Ottawa Hospital Research Institute, Ottawa, Ontario, Canada K1Y 4 E9

Triple-negative breast cancer (TNBC) is a highly metastatic type of breast cancer and one of the largest contributors to cancer mortality in women. Many TNBC treatments that successfully produce general anti-tumor effects preclinical studies fail to display significant impact at the clinical level. This is partially because they do not inhibit the growth of cancer stem cells (CSCs) which have increased ability to evolve into metastatic tumors as well as metabolic pathways commonly associated with increased metastasis. This study will evaluate the potential of four recently proposed TNBC treatments which all successfully reduced tumor viability in vitro and/or in vivo to inhibit genes involved in CSC survival, metastatic metabolomic signature, and immunosuppression. TNBC cell lines and/or patient-derived xenografts were treated with four different treatments: DCC-2036, 9Gy proton irradiation, miR302b+cisplatin combination, and DFX+doxorubicin combination. Genome-wide mRNA profiling was performed on control and treated groups. We assessed the differential expression of genes associated with CSC growth, metastatic metabolomic signature, and immunosuppression in TNBC tumors. DCC-2036 treatment significantly induced the expression of CSC markers and genes associated with the metastatic metabolomic signature and immunosuppression. 9Gy proton irradiation has mixed effects on the expression of our candidate genes, yet mostly induced the expression of stemness and metastasis markers. Both miR302b and DFX dual therapy both failed to inhibit the candidate genes, yet without significantly inducing their expression. GSEA analysis confirmed the results obtained for all four treatments. We concluded that all four treatments failed to significantly impact the expression of protein pathways involved in CSC growth and in metastasis. Therefore, we hypothesize that these treatments will likely not show positive effects in clinical studies. We encourage the researchers to perform more rigorous assays evaluating the impact of their proposed treatments on CSC growth and metastasis in order to more accurately assess the translatable potential of their treatments.

\section{Conflicts of Interest}

The authors have no conflicts of interest to declare.

\section{Authors' Contributions}

SB: President of the Connecting Young Minds (CYM) Undergraduate Research Conference, reviewed abstract submissions to ensure proper formatting standard, assisted undergraduate authors with their submissions, drafted the CYM abstract, drafted and formatted the abstract booklet, and gave final approval of the abstract booklet to be published.

ZS: Co-VP of External Communications of the Connecting Young Minds (CYM) Undergraduate Research Conference, reviewed abstract submissions to ensure proper formatting standard, assisted undergraduate authors with their submissions, contributed to the drafting of the CYM abstract, and gave final approval of the abstract booklet to be published.

MG: Co-VP of Logistics of the Connecting Young Minds (CYM) Undergraduate Research Conference, reviewed abstract submissions to ensure proper formatting standard, assisted undergraduate authors with their submissions, contributed to the drafting of the CYM abstract, and gave final approval of the abstract booklet to be published.

\section{Acknowledgements}

We would like to acknowledge the entire Connecting Young Minds (CYM) Undergraduate Research Conference Executive Team for contributing to the success of CYM's first virtual conference. The executive team that helped make this event possible comprised of Stephanie Bogdan the CYM President, Michelle Gandelman and Dalia Ibrahim the Co-VP Logistics, Zain Saleem and Ghadeer Mohamad the Co-VP External Communications, Skyra Cheng the Volunteer Coordinator, Kathryn Tsao and Khadika Khamal the Co-VP Recruitment, Naila Yoh the VP Translation, Misha Kaniyath the VP Design, Lisa Tran the VP Production, Kaiya Champagne the VP Social Media, and Mohammad Al Kawadri the VP Finance. The conference would also not have been possible without our amazing judges: Dr. Jyn-Yeuan (Eric) Lee, Dr. Erik Harvey Girard, Dr. Adam Shuhendler, and Dr. Vincent Tabard-Cossa. We would also like to thank our wonderful keynote speakers: Dr. Alain St-Amant, Dr. Angel M. Foster, Dr. Barbara Vanderhyden, Dr. John Baenziger, Dr. Michael Downey, Dr. Stephen Gee, and Dr. Jean-Michel Ménard as well as our breakout room leaders: Casey Wong, David Jung, Maria Park, Sam Buchanan, and Anna Ampaw. Lastly, we would like to thank all of our attendees.

\section{Funding}

The Connecting Young Minds Undergraduate Research Conference is funded by Campus Vibez uOttawa. 
UNDERGRADUATE RESEARCH IN NATURAL AND CLINICAL SCIENCE AND TECHNOLOGY (URNCST) JOURNAL

Read more URNCST Journal articles and submit your own today at: https://www.urncst.com

Article Information

Managing Editor: Jeremy Y. Ng

Article Dates: Received Sep 09 21; Published Sep 1621

\section{Citation}

Please cite this article as follows:

Bogdan S, Saleem Z, Gandelman M. 2021 Connecting Young Minds (CYM) Undergraduate Research Conference: 5-minute research presentations. URNCST Journal. 2021 Sep 16: 5(9). https://urncst.com/index.php/urncst/article/view/326

DOI Link: https://doi.org/10.26685/urncst.326

\section{Copyright}

(C) Stephanie Bogdan, Zain Saleem, Michelle Gandelman. (2021). Published first in the Undergraduate Research in Natural and Clinical Science and Technology (URNCST) Journal. This is an open access article distributed under the terms of the Creative Commons Attribution License (https://creativecommons.org/licenses/by/4.0/), which permits unrestricted use, distribution, and reproduction in any medium, provided the original work, first published in the Undergraduate Research in Natural and Clinical Science and Technology (URNCST) Journal, is properly cited. The complete bibliographic information, a link to the original publication on http://www.urncst.com, as well as this copyright and license information must be included.
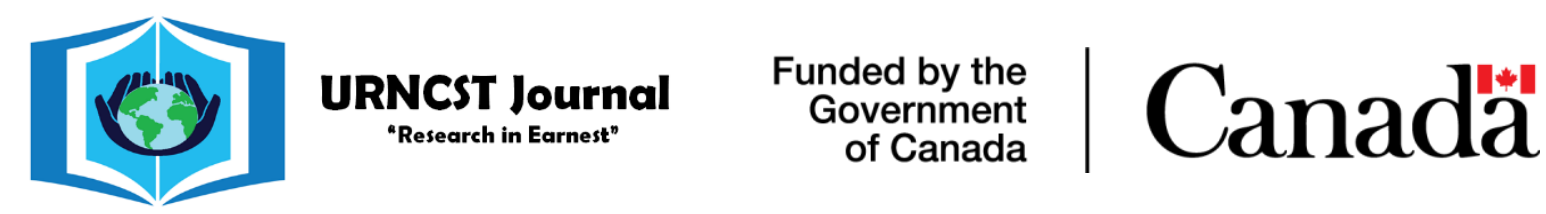

Do you research in earnest? Submit your next undergraduate research article to the URNCST Journal!

| Open Access | Peer-Reviewed | Rapid Turnaround Time | International | | Broad and Multidisciplinary | Indexed | Innovative | Social Media Promoted |

Pre-submission inquiries? Send us an email at info@ urncst.com| Facebook, Twitter and LinkedIn: @URNCST

Submit YOUR manuscript today at https://www.urncst.com! 